Final submitted and accepted version

Reichenberger, I. \& Smith, K.A. (2020). Co-Creating Communities - Fandoms in Tourism Spaces. Tourist Studies, 20(2), 166-181. 


\section{Co-Creating Communities: Fandoms in Tourism Spaces}

Fandoms as expressions of popular culture are characterised by common interests and a sense of belonging and community. Creating and participating in communities is an inherent part of fandom, with tourism providing spaces for this community building to occur face-to-face. Overlaps between tourism and fandoms have been identified in popular culture (for example, film tourism contexts), previous research however is characterized by disciplinary fragmentation and ambiguous transferability. This paper introduces a conceptual framework of fan-based community co-creation, taking into account different intensities of fan involvement as well as factors that contribute to a psychologically perceived sense of community. The framework's applicability to on-site tourism activities and fan-based events is illustrated, and recommendations for its empirical verification are provided.

Keywords: co-creation; fandom; communities; events; involvement; popular culture

\section{Introduction}

The intersections between tourism and popular culture are becoming increasingly visible and important, thus receiving much attention from tourism researchers. A large proportion of this research is directed towards movie and screen tourism (Beeton, 2016; Connell, 2012; Rattanaphinanchai and Rittichainuwat, 2018), with additional studies exploring the roles of music (Lashua et al., 2014), literature (Reijnders, 2011; MacLeod et al., 2018), celebrities (Yen and Croy, 2013) and sports (Hinch and Higham, 2011) in tourism. Visitors' involvement in their respective pop cultural phenomena plays an important role for exploring their tourist experience, making fans a highly relevant visitor segment in certain contexts.

Fans are those with 'a focused interest in a particular topic, subject, or person' (Thorne, 2011: 161), with fandoms being subcultures of like-minded people 'typified by a feeling of closeness to others with the shared interest' (Thorne and Bruner, 2006: 53). Fandoms are an increasingly relevant part of postmodern societies, creating communities that foster social interactions and a sense of belonging based on mutual passions (Plante et al., 2014; Meyer and Tucker, 2007). Two important dimensions of fandom are a perceived group membership as well as the communication with other members (Tsay-Vogel and Sanders, 2017). Digital 
technologies have enabled this communication and connection over common interests for individuals from all over the world (Hillman et al., 2014; Whiteman and Metivier, 2013), allowing phenomena from popular culture including films, tv series, books, music and celebrities to reach new forms of appreciation and importance.

Community building lies at the core of many, if not most, fandom activities, and tourism provides spaces for this community building to occur through direct, personal interactions that are of high importance to members of fandoms (Kington, 2015; Gray et al., 2017). For the tourism industry to provide and manage experiences that fulfil the primarily interaction-related needs of fan-based visitors, it is necessary to have a better understanding of fan-based experiences within tourism spaces as well as the individual and collective meanings these hold. Tourism and events have been shown to offer opportunities for fan-based social interactions to be translated into a face-to-face context (Gyimóthy et al., 2015), yet research grounded in tourism perspectives and adopting a visitor perspective has too often failed to acknowledge the specific characteristics and meanings of fandoms and their members. Fans have either been identified as one of several visitor segments contributing to niches like film tourism (e.g. Roesch, 2009; Macionis, 2004; Peters et al., 2011), or their perspectives were explored within individual and specific cases only (e.g. Lee, 2012; Roberson and Grady, 2015; Alderman et al., 2012) - resulting in knowledge whose transferability is ambiguous.

Outside of the tourism field, fandom has been studied from multiple disciplinary perspectives that are often overlapping and challenging to separate. Management literature has adopted the term 'consumer tribes' (Cova et al., 2007) to predominantly explore marketing and brand loyalty implications of fan-based consumers, although often not within the context of popular culture (e.g. Mitchell and Imrie, 2011; Goulding et al., 2013). The dedicated area of fan studies (e.g. Larsen and Zubernis, 2012; Hills, 2002) is characterised by its multidisciplinary perspective, although predominantly grounded in cultural studies (Ford, 2014). Here, research often takes either an individual, often auto-ethnographic approach (Larsen and Zubernis, 2011) or a macro-social approach where connections between fandoms, the wider (globalised) society and its normative notions are drawn (Fuschillo, 2018; Robertson, 2014; Plante et al., 2014). There are also strong overlaps with media studies due to the object of fandoms and related materials being presented, disseminated and made sense of through various forms of media (Lee, 2011; Tsay-Vogel and Sanders, 2017). Further disciplinary approaches that also often provide a lens through which research in fandom, cultural and media studies is conducted include sociology, social psychology and psychology. With these micro- 
social approaches, exploration tends to focus on the behavioural patterns, social dynamics and communities that underlie and make up fandoms (Crawford, 2003; Schroy et al., 2015; Obst and White, 2005). Although some of this research takes place within tourism spaces, it frequently does not sufficiently acknowledge tourism's nature and contribution (e.g. Waysdorf and Reijnders, 2016; Toy, 2017; Kruse, 2005). This diversity results in a body of literature that often appears fragmented in both its focus and its theoretical and disciplinary groundings (Gyimóthy et al., 2015), making it challenging for tourism research and industry to explore fandoms and their unique characteristics in tourism spaces such as destinations, activities, attractions or events (Roberson and Grady, 2015).

This conceptual paper thus draws upon Gyimóthy et al.'s (2015) call for a less fragmented approach to popular culture's relevance for tourism and the need to underpin individual case studies with a broader social science approach that takes into account not just individual expressions of fandom but the wider concept itself. We propose a framework that utilizes value co-creation to explore the social psychology of fan-based tourist experiences from a micro-social perspective, with a focus on how fans in tourism spaces collectively create a sense of community and therefore fulfil their underlying fan-related needs. Value co-creation as a theoretical foundation has previously been successful in examining the social component of tourism, applied social practices and social interactions, and the different impacts these have on tourist experiences (Reichenberger, 2017; Campos et al., 2016). In doing so, the paper adopts a social constructivist approach that explores 'the meaning-making activity of individuals' (Pernecky, 2012: 1132). Social constructivism is based on the assumption that reality is constructed by our own actions and activities (Kukla, 2013) through social practice and experiences (Small, 1999), thus providing an appropriate paradigm within which to explore the co-creation of fandom-based communities through interaction and participation. The value of this framework lies in its general applicability independent of the object of fandom and characteristics of the respective tourism space, thus reducing the level of fragmentation and low transferability that currently defines research at the intersections of tourism and fandoms. It will contribute to a better understanding of individual visitor experiences in fan-based tourism while providing guidance for practicioners on how to create and manage tourism spaces that cater to the needs of fans.

To begin, different types of fans are explored within the context of serious leisure to provide an initial understanding of how fandoms' unique characteristics can impact the meaning of fan-related tourist activities for fans. This is followed by an exploration of the role 
of communities for fans, as it is at the core of fandom activities and crucial in developing an understanding of how tourism spaces can add value and meaning for fans. Value co-creation as the theoretical foundation will then be adapted to include the distinctiveness of fans and fandoms, resulting in a conceptual framework whose potential for different tourism contexts will be highlighted. The paper will close with concluding remarks.

\section{Fandoms, Serious Leisure and Tourism}

Fans can differ in their intensity of involvement. Thorne (2011) proposes four fanaticism levels to distinguish between different types of fans: dilettante, dedicated, devoted and dysfunctional. Dilettante fans partake in activities that are regarded as common and would apply to most of the population - they may, for example, read a series of books or watch games of a specific sports team when the opportunity presents itself. Only from the dedicated level onwards does a connection between fans and fandom exist, as active lifestyle adjustments are made, and a sense of collective identity and belonging is established. The object of fandom is integrated in individuals' life in a more dominant manner, for example being a regular topic of conversation or, in the case of devoted fans, collecting memorabilia or writing fan fiction. These three types of fan may display behaviour that is viewed by others as unusual or unconventional, but within the prevailing social norms (Thorne and Bruner, 2006). The last type, dysfunctional fans, then engage in behaviour that violates social norms and conventions such as stalking (Thorne, 2011). Similar typologies have been developed for specific fandoms including sports (Hunt, Bristol \& Bashaw, 1999) and rock music fans (Beaven and Laws, 2007). Fan studies also sometimes distinguish between 'followers' and 'fans' to highlight the difference between passive and active behaviour and the importance of collective identity for the latter (Jenkins, 1992; Tulloch and Jenkins, 1995). Dedicated fans thus actively seek to interact with others with the same interest, i.e. a fan-based community. Tourism can therefore provide face-to-face opportunities for these interactions that otherwise occur predominantly digitally (Meyer and Tucker, 2007; Pearson, 2010).

Fandom thus indicates an active as well as emotional involvement and desire for belonging not dissimilar to serious leisure (Stebbins, 2001). We propose that Stebbins' three primary forms of leisure - serious, casual and project-based - align with Thorne's (2011) fanaticism levels. Serious leisure is regarded as 'the systematic pursuit of an amateur, hobbyist or volunteer core activity that people find so substantial, interesting, and fulfilling that [...] 
they launch themselves on a (leisure) career centred on acquiring and expressing a combination of its special skills, knowledge, and experience' (Stebbins, 2007: 5). This implies the existence of professional counterparts; in the case of fans those that are, represent or create the object of fandom. Stebbins has six qualities to identify whether an activity falls within serious leisure: extended perseverance and the execution of efforts, in turn leading to a career with durable benefits, a unique ethos within which leisure activities take place, and the subsequent relevance of the activities for personal identity. These align with the behaviours of devoted and more dedicated fans, which have been described as self-driven and actively involved (Thorne, 2011); this relationship between serious leisure has been identified amongst sport fans (Jones, 2000; Gibson et al., 2017). Stebbins (2007: 5) describes casual leisure as 'an immediately, intrinsically rewarding, relatively short-lived pleasurable core activity, requiring little or no special training to enjoy it'. Casual leisure therefore may be applicable to less dedicated fans whose involvement is often dictated by convenience and ease. It is driven by direct exposure to the respective fan material and enthusiasm of others but is not sustained beyond this (Thorne, 2006). Project-based leisure then consists of infrequent and perhaps one-off activities, possibly encompassing both dilettante fans and dedicated fans subject to more restraints. Fans, depending on their involvement, can therefore exhibit different leisure-based behaviour, attach different meanings to it (especially regarding their relevance for personal as well as collective identity) and construct their lived experiences differently.

To establish, maintain and re-enforce the personal and collective identity (Jenkins, 1992) of dedicated and devoted fans, belonging to and participating in a group where shared experiences are important is not only valued but essential (Connell and Meyer, 2009; Gyimóthy et al., 2015). Attendance at conventions and events and visiting fan-related spaces, as often found in special interest tourism, thus enable interaction with others who share the same interest and provide a marker of affiliation with the fandom community (Coppa, 2014). Fan cultures and fandoms are known to drive special interest tourism (Gyimóthy et al., 2015) where the object of interest can motivate travel to a specific destination (Agarwal et al., 2018; Connell, 2012). Interacting with fellow fans sharing the same interests in places visited specifically for this purpose often functions as a contribution to one's social and collective identity. Gyimóthy et al. (2015) argue for the applicability of serious leisure in that the more fans identify themselves with the subject, the more likely they will be to extend the effort to travel. These occasions add unique temporal components to the often digital realities of being a fan and 
fandom member (Booth, 2010) and provide opportunities to extend one's community involvement to a face-to-face context (Couldry, 1998).

While many visitors to, for example, film tourism destinations do not see themselves as such (Buchmann et al., 2010) and could be classified as 'dilettantes', the more devoted and therefore 'serious' visitors are a recognised segment of special interest markets. However, their experiences and behaviour are often analysed based on how they compare to dilettante (or nonfan) visitors . These tourism-based approaches therefore neglect crucial elements of fan-based tourist behaviour, such as self- and collective identity, the role of fandom communities and social interactions, and the potential relevance of serious leisure and its six qualities to what it is fan-based visitors seek and how they perform their fandom membership. Research that does take these components into account then often provides insight into the realities of fandoms but fails to contribute meaningful insight especially for industry practitioners and how this knowledge can be utilized to create, provide and manage spaces that facilitate such experiences.

\section{Fan-Based Community Building}

The essential connection between fandoms and communities determines the social psychological approach of this paper, focusing on the micro-social level to determine how visitor experiences relate to the presence of and interactions with others, as well as the relevance of social interactions and social belonging as a motivation to engage in fan-related behaviour (Gyimóthy et al., 2015). Understanding fan-based interactions is thus closely related to the concept of community, as the creation of one is at the centre of the fandom's serious leisure efforts and can only be done in cooperation. The relational community, consisting of relationships established based on connections (e.g. due to professions, interests or skills), can thus be transferred temporarily to the territorial notion of community based upon geographical closeness (Gusfield, 1975).

A psychologically perceived sense of community consists of four individual, yet interdependent and reinforcing factors (McMillan and Chavis, 1986; McMillan, 1996), namely membership/spirit, influenceltrust, the fulfilment of needs, and shared emotional connections. These align with Stebbins' (2007) six qualities that identify serious leisure and are likely to also be the perceived benefits fans hope to achieve from participating in and interacting with their fandom while building 'clusters of social affiliations' (Gyimóthy et al., 2015: 21), either in real or in virtual spaces. Membership or, in a revised version, spirit (McMillan, 1996) refers 
to the sense of belonging individuals experience through serious leisure participation, as well as the feeling of being part of a group that others are not. Prior research identified that spirit can be considered a result of publicly displayed membership. For example, participation in public discussions and panels (Kington, 2015; Larsen and Zubernis, 2011), the writing of fan fiction (Pearson, 2010; Hellekson and Busse, 2006) as well as cosplay (costume play) (Waysdorf and Reijnders, 2016; Anderson, 2014; Lamerichs, 2010) help to visibly communicate fandom membership and contribute to a differentiation between less and more involved individuals. Partaking in these activities can be considered a form of serious leisure as they require effort in the form of knowledge and commitment and perseverance to achieve.

Influence or trust then refer to a bidirectional and dynamic concept where power within the community is equally distributed, one's self is validated by conforming to the community's norms and values (see also Stebbins' unique ethos), while members also retain the power to influence developments within the community (McMillan, 1996; McMillan and Chavis, 1986). The trust to perform fan-based self-identity, a crucial component of serious leisure, without fear of judgement in a less self-conscious manner has been identified as an important part of fandom (Lee, 2012; Porter, 2004; Robertson, 2014), based upon visible expressions of membership. The interactions upon which this performance is based create opportunities to influence the atmosphere and the sense of community within, often in proactive manners such as volunteering (Tornes and Kramer, 2015). This, in turn, fulfils a variety of needs of fans, corresponding to the sought durable benefits from serious leisure - these needs often refer directly to the desire to feel part of the fandom community through interactions with other fans (Kington, 2015; Jenkins, 2012; Tsay-Vogel and Sanders, 2017) and in doing so creating a space that allows their fan-related self-identity to become not a secondary but primary factor (Waysdorf and Reijnders, 2016). These three factors of psychologically perceived sense of community are strongly interlinked and, together, are built upon and contribute to the fourth factor, shared emotional connections between members.

Shared emotional connections directly relate to social interactions which help to establish close relationships and strong bonds - these, in turn, encourage one's personal investment in the community and their active engagement in it. Enforced and supported by a sense of membership, trust and active participation, fans can use tourism spaces to create and share emotional connections in a face-to-face context, making community building an expression of serious leisure. Although the final quality of serious leisure, a career, is not reflected in the psychologically perceived sense of community as created by fandoms, it is 
likely that fans' involvement activities and behaviour are neither static nor a-temporal but change and develop over time, as has been shown in the case of sport fans (Crawford, 2003).

All four psychologically perceived sense of community factors have been found to be applicable to a fandom context, also highlighting the strong relevance of fandom communities through conscious identification with it and its impact on perceived self (Obst et al., 2002). What is, however, still unknown is how fandom members collectively create a sense of community within tourism settings, what form their participation within the community and within tourism takes, and how Stebbins' different forms of leisure can be used to understand the differences between types of fans. Value co-creation, putting interactions and active participation in the centre of experiences, will thus be discussed in the next chapter, subsequently utilized to create a conceptual framework that will allow for exploration of these gaps in knowledge.

\section{Value Co-Creation}

Prior research has identified fan-based interactions as a fundamental component of fandoms, instrumental in creating the desired sense of community, and has shed some initial light on their contributions and value outcomes. But to examine how fandom communities are created in tourism spaces it is crucial to explore the social practices at their core. Research thus requires a tool that allows for the exploration of social interactions in spaces where tourism and fandoms merge, acknowledging the special characteristics of fans and their communities.

A framework that has previously been used to explore interactions between social actors and their potential impacts is value co-creation. Focussing on the co-operative creation of experiences through interactions and active participation, social practices amongst individuals and their meaning are explored to make sense of how people come together and what factors influence their resulting co-creational practices. Based on the argument that value only exists once a consumer utilizes a service, "value is always co-created, jointly and reciprocally, in interactions among providers and beneficiaries through the integration of resources and application of competences' (Vargo et al., 2008: 146). For tourism managers, value co-creation opens up possibilities to utilize visitors themselves in the creation of memorable experiences (Andrades and Dimanche, 2014), and it also provides opportunities to understand how individual tourist experiences are shaped by oneself and others. While the concept originally focused only on interactions between customers and producers from 
management and organisational perspectives (Cabiddu et al., 2013), it has since been adopted by other disciplines due to its focus on cooperative action and experiences - including psychology (Campos et al., 2018).

Here, co-creation places individuals' interactions with other social actors as well as their active participation in the centre of experiences (Volo, 2009; Prahalad and Ramaswamy, 2004; Rihova et al., 2015). Individuals therefore co-create their own experiences - both by interacting with others and by actively participating in their experience in physical and mental ways, resulting in additional value and benefits (Campos et al., 2018; Prebensen et al., 2014). Research has identified a variety of co-creational value outcomes, including memorability, the acquisition of additional knowledge, fun, entertainment and emotional benefits (Reichenberger, 2017; Campos et al., 2016). The experiential context in which this occurs has been referred to as the 'experiencescape' (O'Dell and Billing, 2005), influenced by physical, social and organisational factors, highlighting not only the relevance of other social actors but also of the physical environment and organisational dynamics (Cutler and Carmichael, 2010) that represent the industry context. This makes it possible to apply the concept of value cocreation to a wide variety of different, often commercial, tourism settings and allows for the identification of factors that both encourage and discourage visitors' ability to actively cocreate their experiences with others and, though this, add further dimensions of value.

While research has predominantly examined co-creational processes from management perspectives, increasing attention has been paid on customer-to-customer (C2C) co-creation (Campos et al., 2016; Llinares Millán et al., 2016; Reichenberger, 2017). Value co-creation is thus applicable to tourists' interactions with a wide variety of social actors, therefore posing an especially suitable framework to explore the connections between fandom and tourism in more detail, as fandoms are predominantly built upon and revolve around social interactions between their members. Prior research has also identified a 'communitas' component within value cocreation, where social actors establish camaraderie and feel united by a sense of belonging, often while being placed within liminoid and extraordinary environments (Rihova et al., 2013) - a phenomenon also observed within fandoms, communities whose members experience a sense of belonging in unique spaces (Moller, 2002; Obst et al., 2002). In summary, value cocreation lends itself well as a tourism-based and tested framework to explore the social practices of fans in creating a sense of perceived community, as it considers the fans themselves, their individual as well as micro-social practices and potential influential factors. 


\section{A Framework for Fan-Based Community Co-Creation in Tourism}

Applying prior conceptualisations of value co-creation to fandom-based tourism spaces, however, would limit their ability to identify and understand the specific relevance of fandoms and how tourism can provide spaces for the creation of fan-based communities. The factors contributing to a psychologically perceived sense of community are at the core of fanbased tourist experiences, and differentiations between fans' involvement based on Thorne's (2011) scale are required to account for diverse expressions of fandom and their relevance for self-identity. Figure 1 thus presents a framework for fan-based community co-creation in tourism, based on Campos et al.'s (2018) psychological on-site co-creation framework, that will allow for an exploration of the social component of fan-based tourist experiences and how it is utilized to contribute to the building of communities. It provides an overview of the social psychological components relevant for positive fan-based experiences, situated within and applicable to the experiential context of tourism spaces. The framework identifies how fans' and visitors' active participation and social interactions contribute to the creation of a perceived sense of community and how external factors under managerial control can contribute to this. Further, it will highlight how prior research findings support the applicability of this framework. While no study has specifically focused on fan-based interactions or community co-creation, incidental findings strongly support the applicability of the proposed conceptual framework to a variety of on-site tourist activities, including film locations, special interest tours and theme parks.

Insert Figure 1 Here 


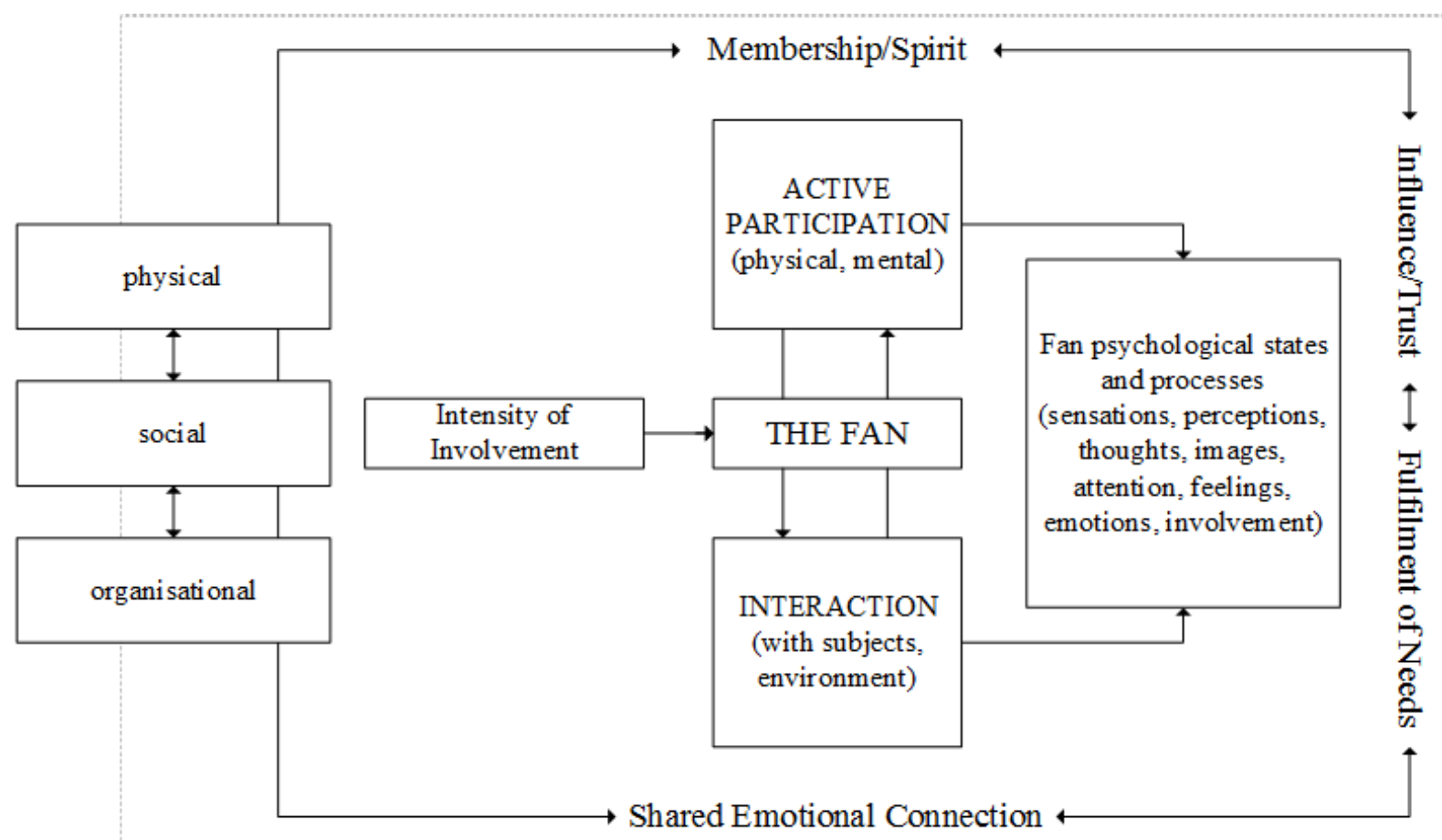

The fan sits at the centre of the framework, their further role subject to their intensity of involvement as highlighted by Thorne (2011) and the type of leisure they pursue through fan-based activities (Stebbins, 2007). This allows for the exploration of different types of fans and takes into account the variations between dilettante, dedicated, devoted and dysfunctional fans and therefore the distinctions between casual, serious and project-based leisure. Integrating the fan involvement will address one of the main gaps in hitherto existing fandomtourism literature, where experiences of often significantly differently involved visitors, attaching different weight and meanings to their activities, were grouped and examined together. Different levels of involvement amongst fans have been found to determine how visitors engage with each other and the environment (Roesch, 2009; Waysdorf and Reijnders, 2016; Carl et al., 2007; Kim and Assaker, 2014).

The core components of value co-creation - active physical and/or mental participation and the interaction with subjects and the environment - have been retained from Campos et al. (2018) as the foundational elements of fandom-based community building, as being a fan is more than just passive consumption (Stanfill and Condis, 2014). It has been shown that fans in tourism spaces participate actively through visible expressions of fandom (Waysdorf and Reijnders, 2016) as well as mentally by experiencing closer connections to their respective fandom universe (Kington, 2015). These then contribute to a variety of psychological states 
and processes. Although little is known about the specific types of interaction and participation apart from cosplay (Waysdorf and Reijnders, 2016), information exchange (Roesch, 2009) and interacting with props and environmental settings to recreate and photograph scenes (Kim, 2010), it has been shown that these can influence satisfaction levels, and re-visit as well as recommendation intentions (Kim, 2012). This also contributes to the perception of multiple space identities and the immersion within (e.g. experiencing the environment as their fictional identity as opposed to real) (Alderman et al., 2012). These visible displays of fandom, expressed through interactions and participations, are directly and interdependently connected with a perceived sense of community.

The co-creational process thus creates and is embedded within the psychologically perceived sense of community (McMillan and Chavis, 1986). It is important to note that these cannot be separated from each other and exist only in combination - co-creation contributes to a sense of community, and a sense of community is required for fandom co-creational practices to occur. Participation and interaction as well as the resulting psychological states and processes are dependent upon and contribute to a sense of membership and spirit (Porter, 2004). For example, visible expressions of fandom such as their level of preparation and knowledge, as well as costumes and memorabilia brought on-site (Roesch, 2009), are therefore a visible identifier of one's commitment to the fandom and signify group membership (Waysdorf and Reijnders, 2016). If conducted together with other fans a sense of spirit is created (Obst et al., 2002). This, in turn, provides fans with the influence and power to create an atmosphere of trust that allows them to visibly express their fandom less self-consciously (Lee, 2012), and through adherence to those fans influence the form and shape of the fandom community that is co-created in these spaces. Through these participative and interaction-based experience elements, shared emotional connections are created. They, in turn, fulfil the needs of fan visitors to engage with other fans in a community setting to establish closer connections to their respective fandom (Roesch, 2009; Buchmann et al., 2010).

Campos et al.'s (2018) original outcome of value co-creation in on-site tourism spaces, namely experience memorability, has been excluded in this particular context. Current research lacks insight into the type of value fans gain from their co-creational community building in tourism spaces, and as fulfilment of needs is a core component of a perceived sense of community further research is required to clearly examine the role and type of value outcomes and their temporal relations. However, the physical, social and organisational influential factors have been retained. Originally, these were considered one-directional and were placed outside 
of the co-creation process. In the context of fan-based tourism, however, they can be considered both externally provided and internally co-created, as the community factor 'influence' is considered dynamic and bidirectional. The arrangement of the physical environment, the social actors within, and the organisational and managerial components can thus originate from fanbased co-creation and external arrangements alike. This has been shown especially in the context of fan-based events and conventions, where the lines between fan-based visitor and cocreation facilitator are blurred (Tornes, 2014; Peaslee et al., 2014).

Although these findings confirm the suitability of the proposed conceptual framework for tourism spaces, all are fragmented due to their varied and disconnected origin. In addition, it is unknown which role physical, social and organisational factors play for the individual as well as the macro-social level and what their relation to fan-based community co-creation is. The impact of involvement and form of leisure on participation and interaction, the potential impact and manifestation of the serious leisure career stage and therefore the a-temporal characteristic of being a fan, as well as the varied expressions of these have not yet been explored from a tourism perspective. No direct links have been established between fans' activities, their connection to a perceived sense of community, and the interdependencies of both within tourism. Applying the proposed framework to one cohesive tourism space will allow to fill these gaps in our current knowledge, in turn providing more in-depth insight into how fans collectively create a sense of community and tourism spaces and how the tourism industry can create and manage spaces that facilitate the fulfilment of their needs.

\section{Conclusion}

This paper has introduced a conceptual framework utilizing value co-creation that allows for the exploration of the social psychology of fan-based tourist experiences from a micro-social perspective, with a focus on how fans in tourism spaces collectively create a sense of community and therefore fulfil their underlying fan-related needs. Prior research on the intersections between tourism and popular culture has often neglected to explore the wider role of fandoms, their specific characteristics and meanings they hold for members - or, in contrast, is fragmented in its consistent use of specific cases and disciplinary variety. By exploring the central role of communities for fandoms and fans and their contributing factors (McMillan, 1996) in relation to serious leisure (Stebbins, 2007) as well as fan-related involvement (Thorne, 2011) from a non-case-based perspective, the framework shows how these can be translated to 
and explored within tourism spaces. A psychological adaptation of the concept of value cocreation (Campos et al., 2018) has been expanded to include relevant components for fandoms and fans, and the newly created conceptual framework for fan-based community co-creation will function as a tool to explore social practices and interactions amongst fans in tourism settings in a tailored and cohesive manner. The inclusion of physical and organizational factors (Cutler and Carmichael, 2010) acknowledges the influence of the managerial tourism context, which will allow managers to better understand how to encourage and facilitate co-creational practices that positively contribute to a perceived sense of community amongst fandom members and fulfils the needs of fan visitors.

Examining research that connects fandoms with on-site tourism activities and events has confirmed the applicability of the individual framework components. Simultaneously, a number of gaps in our understanding of fandom-based community co-creation in tourism spaces were highlighted. Further research should thus focus on exploring the phenomenon holistically and comprehensively within a certain setting to examine the relevance, role and relationships of and with physical, social and organisational factors to understand the tourism industry's opportunities in creating and managing spaces that allow for positive fandom community experiences. Furthermore, it is uncertain how different forms of leisure and different levels of involvement manifest themselves in behaviour and experiences, as well as over time. While the link between these practices and a perceived sense of community is strongly supported by prior research, it is still unknown what form and shape this takes, how different practices and community factors are interlinked, and how organised tourism activities differ from independently undertaken ones. In addition, the needs that fans aim to fulfil through entering fan-related tourism spaces and engaging in co-creational community building are not clearly identified, neither are the value outcomes.

For application of the framework to fill the above mentioned gaps, qualitative approaches that allow for hermeneutic examination of the phenomenon are suited for empirical verification of the framework. Further research can also address the framework's limitation of focussing on the face-to-face visitor perspective only as well as its focus on the temporality of an activity. Its applicability to contexts such as fan-based volunteering (Kington, 2015; Tornes and Kramer, 2015), fan labor (Peaslee et al., 2014), fan activism (Brough and Shresthova, 2011; Jenkins, 2015) or even online contexts (Hillman et al., 2014) may also be explored. Very little research on the intersections of popular culture and tourism has been conducted that sufficiently acknowledges the unique characteristics of both fandoms and tourism holistically, and this 
paper proposes a stepping stone for further investigation of an increasingly relevant component of the current tourism landscape. 


\section{References}

Agarwal S, Busby G and Huang R. (2018) Special Interest Tourism: Concepts, Contexts and Cases, Wallingford: CABI.

Alderman DH, Benjamin, Stefanie K and Schneider PP. (2012) Transforming Mount Airy into Mayberry: Film-Induced Tourism as Place-Making. Southeastern Geographer 52: 212-239.

Anderson K. (2014) Actualized Fantasy at Comic-Con and the Confessoins of a "Sad Cosplayer". In: Bolling B and Smith MJ (eds) It Happens at Comic-Con. Ethnographic Essays on a Pop Culture Phenomenon. Jefferson: McFarland \& Company, 16-28.

Andrades L and Dimanche F. (2014) Co-creation of experience value: a tourist behaviour approach. In: Prebensen NK, Chen JS and Uysal M (eds) Creating experience value in tourism. Wallingford: CABI International, 95-112.

Beaven Z and Laws C. (2007) 'Never Let Me Down Again'1: Loyal customer attitudes towards ticket distribution channels for live music events: a netnographic exploration of the US leg of the Depeche Mode 2005-2006 World Tour. Managing Leisure 12: 120-142.

Beeton S. (2016) Film-induced tourism, Bristol: Channel View Publications.

Booth P. (2010) Digital fandom: New media studies, New York: Peter Lang.

Brough MM and Shresthova S. (2011) Fandom meets activism: Rethinking civic and political participation. Transformative Works and Cultures 10.

Buchmann A, Moore K and Fisher D. (2010) Experiencing Film Tourism. Authenticity \& Fellowship. Annals of Tourism Research 37: 229-248.

Cabiddu F, Lui T-W and Piccoli G. (2013) Managing Value Co-Creation in the Tourism Industry. Annals of Tourism Research 42: 86-107.

Campos AC, Mendes J, do Valle PO, et al. (2016) Co-Creation Experiences: Attention and Memorability. Journal of Travel \& Tourism Marketing 33: 1309-1336.

Campos AC, Mendes J, do Valle PO, et al. (2018) Co-creation of tourist experiences: a literature review. Current Issues in Tourism 21: 369-400.

Carl D, Kindon S and Smith K. (2007) Tourists' Experiences of Film Locations: New Zealand as 'Middle-Earth'. Tourism Geographies 9: 49-63.

Connell J. (2012) Film tourism - Evolution, progress and prospects. Tourism Management 33: 10071029.

Connell J and Meyer D. (2009) Balamory revisited: An evaluation of the screen tourism destinationtourist nexus. Tourism Management 30: 194-207.

Coppa F. (2014) Fuck yeah, Fandom is Beautiful. The Journal of Fandom Studies 2: 73-82.

Couldry N. (1998) The view from inside the 'simulacrum': visitors' tales from the set of Coronation Street. Leisure Studies 17: 94-107.

Cova B, Kozinets RV and Shankar A. (2007) Consumer Tribes, Amsterdam: Butterworth-Heinemann. 
Crawford G. (2003) The Career of the Sport Supporter: The Case of the Manchester Storm. Sociology 37: 219-237.

Cutler SQ and Carmichael BA. (2010) The dimensions of the tourist experience. In: Morgan M, Lugosi $\mathrm{P}$ and Ritchie JRB (eds) The tourism and leisure experience: Consumer and managerial perspectives. Bristol: Channel View Publications, 3-26.

Earnheardt AC, Haridakis PM and Hugenberg BS. (2012) Sports fans, identity and socialization: Exploring the fandemonium. Lanham: Lexington Books.

Ford S. (2014) Fan studies: Grappling with an 'Undisciplined' discipline. The Journal of Fandom Studies 2: 53-71.

Fuschillo G. (2018) Fans, fandoms, or fanaticism? Journal of Consumer Culture.

Gibson H, Willming C and Holdnak A. (2017) "We're Gators ... Not Just Gator Fans": Serious Leisure and University of Florida Football. Journal of Leisure Research 34: 397-425.

Goulding C, Shankar A and Canniford R. (2013) Learning to be tribal: facilitating the formation of consumer tribes. European Journal of Marketing 47: 813-832.

Gray J, Sandvoss C and Harrington CL. (2017) Fandom: Identities and communities in a mediated world. New York: New York University Press.

Gusfield JR. (1975) Community: A critical response: Harper \& Row New York.

Gyimóthy S, Lundberg C, Lindström KN, et al. (2015) Popculture Tourism. Tourism Research Frontiers: Beyond the Boundaries of Knowledge 20: 13-26.

Hellekson K and Busse K. (2006) Fan fiction and fan communities in the age of the Internet: new essays. Jefferson: McFarland \& Company.

Hillman S, Procyk J and Neustaedter C. (2014) Tumblr fandoms, community \& culture. Computer Supported Cooperative Work and Social Computing. Baltimore, 285-288.

Hills M. (2002) Fan cultures, London: Routledge.

Hinch T and Higham J. (2011) Sport tourism development, Clevedon: Channel View Publications.

Hoppen A, Brown L and Fyall A. (2014) Literary tourism: Opportunities and challenges for the marketing and branding of destinations? Journal of Destination Marketing \& Management 3: $37-47$.

Jenkins H. (1992) Textual poachers: Studies in culture and communication, London: Routledge.

Jenkins H. (2012) Super-powered fans - the many worlds of San Digeo's Comic-Con. Boom: A Journal of California 2: 22-36.

Jenkins H. (2015) Cultural Acupuncture: Fan Activism and the Harry Potter Alliance. In: Geraghty L (ed) Popular Media Cultures. London: Palgrave Macmillan, 206-229.

Jones I. (2000) A model of serious leisure identification: the case of football fandom. Leisure Studies 19: $283-298$.

Kim S. (2010) Extraordinary Experience: Re-enacting and Photographing at Screen Tourism Locations. Tourism and Hospitality Planning \& Development 7: 59-75. 
Kim S. (2012) The Relationships of On-Site Film-Tourism Experiences, Satisfaction, and Behavioral Intentions: The Case of Asian Audience's Responses to a Korean Historical TV Drama. Journal of Travel \& Tourism Marketing 29: 472-484.

Kim S and Assaker G. (2014) An Empirical Examination of the Antecedents of Film Tourism Experience: A Structural Model Approach. Journal of Travel \& Tourism Marketing 31: 251268.

Kington CS. (2015) Con culture: A survey of fans and fandom. The Journal of Fandom Studies 3: 211228.

Kruse RJ. (2005) The Beatles as Place Makers: Narrated Landscapes in Liverpool, England. Journal of Cultural Geography 22: 87-114.

Kukla A. (2013) Social constructivism and the philosophy of science: Routledge.

Lamerichs N. (2010) Stranger than fiction: Fan identity in cosplay. Transformative Works and Cultures 7.

Larsen K and Zubernis L. (2011) Fandom at the crossroads: Celebration, shame and fan/producer relationships, Newcastle upon Tyne: Cambridge Scholars Publishing.

Larsen K and Zubernis L. (2012) Fan culture: Theory/practice. Newcastle upon Tyne: Cambridge Scholars Publishing.

Lashua B, Spracklen K and Long P. (2014) Introduction to the special issue: Music and Tourism. Tourist Studies 14: 3-9.

Lee C. (2012) "Have Magic, Will Travel": Tourism and Harry Potter's United (Magical) Kingdom. Tourist Studies 12: 52-69.

Lee H-K. (2011) Participatory media fandom: A case study of anime fansubbing. Media, Culture \& Society 33: 1131-1147.

Llinares Millán C, Garzon D and Navarro S. (2016) C2C interactions creating value in the Route of Santiago. Journal of Business Research 69: 5448-5455.

Macionis N. (2004) Understanding the Film-Induced Tourist. In: Frost W, Croy G and Beeton S (eds) International Tourism and Media Conference Proceedings. Melbourne: Tourism Research Unit, Monash University, 86-97.

MacLeod N, Shelley J and Morrison AM. (2018) The touring reader: Understanding the bibliophile's experience of literary tourism. Tourism Management 67: 388-398.

McMillan DW. (1996) Sense of Community. Journal of Community Psychology 24: 315-325.

McMillan DW and Chavis DM. (1986) Sense of Community: A Definition and Theory. Journal of Community Psychology 14: 6-23.

Meyer MDE and Tucker MHL. (2007) Textual Poaching and Beyond: Fan Communities and Fandoms in the Age of the Internet. Review of Communication 7: 103-116.

Mitchell C and Imrie BC. (2011) Consumer tribes: membership, consumption and building loyalty. Asia Pacific Journal of Marketing and Logistics 23: 39-56. 
Moller M. (2002) Reclaiming the game: Fandom, community and globalisation. Journal of Australian Studies 26: 211-220.

O'Connor N and Kim S. (2013) Media-Related Tourism Phenomena: A Review of the Key Issues. In: Scarles C (ed) Mediating the Tourist Experience. London: Routledge, 13-32.

O'Connor N and Kim S. (2014) Pictures and prose: exploring the impact of literary and film tourism. Journal of Tourism and Cultural Change 12: 1-17.

O'Dell T and Billing P. (2005) Experiencescapes: Tourism, culture and economy: Copenhagen Business School Press DK.

Obst P, Zinkiewicz L and Smith SG. (2002) Sense of Community in Science Fiction Fandom Part 1: Understanding Sense of Community in an International Community of Interest. Journal of Community Psychology 30: 87-103.

Obst PL and White KM. (2005) An exploration of the interplay between psychological sense of community, social identification and salience. Journal of Community \& Applied Social Psychology 15: 127-135.

Pearson R. (2010) Fandom in the Digital Era. Popular Communication 8: 84-95.

Peaslee RM, El-Khoury J and Liles A. (2014) The media festival volunteer: Connecting online and onground fan labor. Transformative Works \& Cultures 15.

Pernecky T. (2012) Constructionism. Critical Pointers for Tourism Studies. Annals of Tourism Research 39: 1116-1137.

Peters M, Schuckert M, Chon K, et al. (2011) Empire and Romance: Movie-Induced Tourism and the Case of the Sissi Movies. Tourism Recreation Research 36: 169-180.

Plante CN, Roberts SE, Reysen S, et al. (2014) "one of us": Engagement with fandoms and global citizenship identification. Psychology of Popular Media Culture 3: 49-64.

Porter JE. (2004) Pilgrimage and the IDIC ethic: Exploring Star Trek convention attendance as pilgrimage. In: Badone $\mathrm{E}$ and Roseman SR (eds) Intersecting journeys: The anthropology of pilgrimage and tourism. Urbana: University of Illinois Press, 160-179.

Prahalad CK and Ramaswamy V. (2004) Co-creation experiences: The next practice in value creation. Journal of Interactive Marketing 18: 5-14.

Prebensen NK, Chen JS and Uysal M. (2014) Creating Experience Value in Tourism. Wallingford: CABI International.

Rattanaphinanchai S and Rittichainuwat BN. (2018) Film - induced tourism in Thailand: an influence of international tourists' intention to visit film shooting location. International Journal of Tourism Sciences 18: 325-332.

Reichenberger I. (2017) C2C value co-creation through social interactions in tourism. International Journal of Tourism Research 19: 629-638.

Reijnders S. (2011) Stalking the count. Annals of Tourism Research 38: 231-248.

Rihova I, Buhalis D, Moital M, et al. (2015) Conceptualising Customer-to-customer Value Co-creation in Tourism. International Journal of Tourism Research 17: 356-363. 
Rihova I, Buhalis D, Moital M, et al. (2013) Social layers of customer-to-customer value co-creation. Journal of Service Management 24: 553-566.

Roberson R and Grady M. (2015) The "Shawshank Trail": A Cross Disciplinary Study in Film Induced Tourism and Fan Culture. AlmaTourism 6: 47-66.

Robertson VLD. (2014) Of ponies and men: My Little Pony: Friendship is Magic and the Brony fandom. International Journal of Cultural Studies 17: 21-37.

Roesch S. (2009) The Experiences of Film Location Tourists, Bristol: Channel View Publications.

Schroy C, Plante CN, Reysen S, et al. (2015) Different Motivations as Predictors of Psychological Connection to Fan Interest and Fan Groups in Anime, Furry, and Fantasy Sport Fandoms. The Phoenix Papers 2: 148-167.

Small J. (1999) Memory-work: a method for researching women's tourist experiences. Tourism Management 20: 25-35.

Stanfill M and Condis M. (2014) Fandom and/as labor. Transformative Works and Cultures 15.

Stebbins RA. (2001) Serious Leisure. Society May/June: 53-57.

Stebbins RA. (2007) Serious leisure: A perspective for our time, New Brunswick: Transaction Publishers.

Thorne S. (2011) An exploratory investigation of the theorized levels of consumer fanaticism. Qualitative Market Research: An International Journal 14: 160-173.

Thorne S and Bruner GC. (2006) An exploratory investigation of the characteristics of consumer fanaticism. Qualitative Market Research: An International Journal 9: 51-72.

Tornes M. (2014) The Volunteer Experience: Meaning, Motivation and Role Conflict in a Temporary Organization. In: Bolling B and Smith MJ (eds) It Happens at Comic-Con: Ethnographic Essays on a Pop Culture Phenomenon. Jefferson: McFarland \& Company, 169-182.

Tornes M and Kramer MW. (2015) The Volunteer Experience in Temporary Organizations: Volunteer Role Negotiation and Identification in a Pop-Culture Convention. Communication Studies 66: 590-606.

Toy JC. (2017) Constructing the fannish place: Ritual and sacred space in a Sherlock fan pilgrimage. The Journal of Fandom Studies 5: 251-266.

Tsay-Vogel M and Sanders MS. (2017) Fandom and the search for meaning: Examining communal involvement with popular media beyond pleasure. Psychology of Popular Media Culture 6: 3247.

Tulloch J and Jenkins H. (1995) Science Fiction Audiences: Watching Star Trek and Doctor Who, New York: Routledge.

Vargo SL, Maglio PP and Akaka MA. (2008) On value and value co-creation: A service systems and service logic perspective. European Management Journal 26: 145-152.

Volo S. (2009) Conceptualizing Experience: A Tourist Based Approach. Journal of Hospitality Marketing \& Management 18: 111-126. 
Waysdorf A and Reijnders S. (2016) Immersion, authenticity and the theme park as social space: Experiencing the Wizarding World of Harry Potter. International Journal of Cultural Studies 21: 173-188.

Whiteman N and Metivier J. (2013) From post-object to "Zombie" fandoms: The "deaths" of online fan communities and what they say about us. Participations 10: 270-298.

Yen C-H and Croy WG. (2013) Film tourism: celebrity involvement, celebrity worship and destination image. Current Issues in Tourism: 1-18. 